\title{
Combustion mode design with high efficiency and low emissions controlled by mixtures stratification and fuel reactivity
}

\author{
Hu Wang, Zunqing Zheng, Haifeng Liu and Mingfa Yao*
}

State Key Laboratory of Engines, Tianjin University, Tianjin, China

This paper presents a review on the combustion mode design with high efficiency and low emissions controlled by fuel reactivity and mixture stratification that have been conducted in the authors' group, including the charge reactivity controlled homogeneous charge compression ignition $(\mathrm{HCCl})$ combustion, stratification controlled premixed charge compression ignition combustion, and dual-fuel combustion concepts controlled

\section{OPEN ACCESS}

Edited by:

Stephen Anthony Ciatti,

Argonne National Laboratory, USA

Reviewed by:

Derek Splitter,

Oak Ridge National Laboratory, USA

Martin Wissink

Oak Ridge National Laboratory, USA

${ }^{*}$ Correspondence:

Mingfa Yao,

State Key Laboratory of Engines, Tianjin University, No. 92 Weijin Road, Nankai District, Tianjin 300072, China

y_mingfa@tju.edu.cn

Specialty section: This article was submitted to Engine and Automotive Engineering, a section of the journa Frontiers in Mechanical Engineering

Received: 25 June 2015 Accepted: 05 August 2015 Published: 24 August 2015

Citation:

Wang $H$, Zheng Z, Liu H and Yao $M$ (2015) Combustion mode design with high efficiency and low emissions controlled by mixtures stratification and fuel reactivity.

Front. Mech. Eng. 1:8. doi: 10.3389/fmech.2015.00008 by both fuel reactivity and mixture stratification. The review starts with the charge reactivity controlled $\mathrm{HCCl}$ combustion, and the works on $\mathrm{HCCl}$ fueled with both high cetane number fuels, such as dimethyl ether and $n$-heptane, and high octane number fuels, such as methanol, natural gas, gasoline, and mixtures of gasoline/alcohols, are reviewed and discussed. Since single fuel cannot meet the reactivity requirements under different loads to control the combustion process, the studies related to concentration stratification and dual-fuel charge reactivity controlled HCCl combustion are then presented, which have been shown to have the potential to achieve effective combustion control. The efforts of using both mixture and thermal stratifications to achieve the auto-ignition and combustion control are also discussed. Thereafter, both charge reactivity and mixture stratification are then applied to control the combustion process. The potential and capability of thermal-atmosphere controlled compound combustion mode and dual-fuel reactivity controlled compression ignition/highly premixed charge combustion mode to achieve clean and high efficiency combustion are then presented and discussed. Based on these results and discussions, combustion mode design with high efficiency and low emissions controlled by fuel reactivity and mixtures stratification in the whole operating range is proposed.

Keywords: $\mathrm{HCCl}$, combustion mode design, dual-fuel, reactivity, stratification

\section{Introduction}

Clean and high efficiency combustion technology is the key to meet the even stringent emission legislations for internal combustion (IC) engines. For conventional diesel engines, the auto-ignition and combustion highly depend on the spray breakup and mixing events. Due to the nature of mixing controlled combustion process, local rich regions exist in the combustion chamber, which favors the formation of soot or particulate matter; there also exists stoichiometric regions, results 
in high combustion temperature and hence high NOx emissions. Therefore, the combustion evolution process enters both the high soot and high NOx formation regions in the $\Phi$-T map, thus the traditional trade-off between soot and NOx emissions exists in conventional combustion regimes (Reitz, 2013).

The available mixing time, known as the ignition delay, usually expressed as the interval between the start of injection (SOI) and start of combustion (SOC) in IC engines, is the key parameter to improve the premixed mixture and to suppress the soot formation. Ideally soot can be totally eliminated if the fuel-air mixture is homogeneous, the low equivalence ratio also prevents the formation of NOx due to the low combustion temperature, thus ultra-low soot and NOx emissions can be obtained simultaneously. This is the essential concept of homogeneous charge compression ignition (HCCI) combustion. In addition, the auto-ignition and combustion process of HCCI combustion is controlled by chemical kinetics, adhering with high volumetric heat release process, together with reduced heat release loss due to the low combustion temperature, thus high thermal efficiency can also be obtained. Therefore, HCCI combustion has the potential to be highly efficient with ultra-low emissions (Yao et al., 2009).

However, the major challenges in the operation of HCCI engines are the effective control of ignition timing and combustion rate, essentially the combustion phasing (represented by CA50 timing, time of 50\% accumulated heat release) and peak pressure rise rate [PPRR, usually controlled to be lower than $1.0 \mathrm{MPa} /$ crank angle (CA) degree], which are determined by the local distributions of temperature, pressure, and mixture composition. Since the mixture is homogeneous, once the auto-ignition occurs, there is no direct way to achieve effective control of the combustion rate, results in high PPRR, which in turn limits the maximum achievable loads. In addition, due to the low equivalence ratio, the combustion efficiency is considerably lower than conventional combustion, thus high unburnt hydrocarbon (UHC) and carbon monoxide (CO) emissions are also problems associated with HCCI combustion. Therefore, from the combustion control perspective, it is desirable to develop effective measures to achieve both auto-ignition timing and combustion phasing control to utilize the advantages of HCCI combustion concept (Yao et al., 2009).

Fuel property optimization has been found to be an effective measure to manipulate the HCCI combustion process. Fuel reactivity control through port injection of two fuels with quite different reactivity (such as $n$-heptane and iso-octane) offers an effective way to achieve HCCI combustion phasing control. It has been pointed out that high cetane number fuels can be beneficial for HCCI combustion under low load conditions, while high octane number fuels are helpful for HCCI load extensions. The overall reactivity of the fuel-air mixture can be altered by changing the ratio between the high reactivity and low reactivity fuels. In this way, both auto-ignition timing and combustion phasing can be well controlled through dual-fuel HCCI operation (Yao et al., 2004).

However, although the dual-fuel HCCI combustion could extend the stable HCCI operation range, the maximum load is still restricted by the PPRR to be within low loads, thus other ways should be taken to suppress the combustion reaction rate, especially under high load conditions. Richter et al. (2010) found that the charge inhomogeneity was potentially significant and played an important role in the combustion process. Mixture stratification changes the local equivalence ratios and therefore can be regarded as a potential mechanism for HCCI combustion control.

From this point, mixture stratification has been studied in addition to the charge reactivity to control the HCCI combustion. In this compound combustion concept, either single fuel or dual-fuel with different reactivity was introduced into the combustion chamber through both port and direct injections (DIs). If a single fuel was used, also known as premixed charge compression ignition (PCCI), the ratio between the premixed injections and DI fuel, as well as the DI timing, can be used to control the mixture stratification. In this way, the amount of the fuel residing in the quenching zones can be reduced in stratification combustion compared to the pure HCCI combustion, the PPRR and UHC can also be effectively reduced. Consequently, the fuel economy could be improved and the HCCI operating range can be extended. However, both $\mathrm{CO}$ and $\mathrm{NOx}$ emissions increase with the degree of stratification. In addition, the engine still could not run in full load mode.

In the dual-fuel compound combustion concept, the combustion can be classified into two regimes, determined by the premixed and DI fuels' reactivity. A thermo-atmosphere compound combustion regime can be operated by port injection high reactivity fuel [high cetane number fuel, such as dimethyl ether (DME)] and DI low reactivity fuel (high octane number fuel, such as methanol). The early combustion of the premixed fuel supplies a thermo-atmosphere so that the following directly injected fuel can be ignited quickly after undergoing a short ignition delay. With this compound combustion concept, the combustion characteristic can be regarded as a combination of HCCI (low-temperature reaction (LTR) and high temperature reaction (HTR) of premixed high reactivity fuel) and diffusion combustion (heat release of DI low reactivity fuel). The engine can be run at much higher loads compared to the pure HCCI and single fuel PCCI combustion modes, with low UHC and CO emissions, while the NOx emission can be controlled by the DI injection strategy.

By contrast, a reactivity controlled compression ignition (RCCI) or highly premixed charge combustion (HPCC) can be achieved by port injection of low reactivity fuel (high octane number fuel, such as gasoline) and DI of high reactivity fuel (high cetane number fuel, such as diesel) (Reitz and Duraisamy, 2015). In this mode, most of the fuel was introduced through port injection, and the DI high reactivity fuel acts as the ignition source. The ratio between the premixed and DI fuels, as well as the DI injection strategy, can be used to control both the combustion rate and combustion phasing. Since both charge reactivity and mixture stratifications exist in the chamber, the combustion duration can be prolonged, results in reduced PPRR. As a result, much higher operating loads can be achieved. In addition, ultra-low NOx and soot emissions can also be obtained simultaneously with this combustion concept, together with high thermal efficiency due to the reduced heat transfer loss. This compound dual-fuel combustion concept has the potential to achieve clean and high 
efficiency combustion within much wider operation ranges. Even though, how to achieve and optimize the combustion in the full load range still remains as the challenge for the development of this novel combustion concept.

This objective of this paper is to present a review on the combustion mode design with high efficiency and low emissions controlled by mixture stratification and charge reactivity that have been conducted in the authors' group. The authors are aware of that there are a lot of relevant studies in this research direction. However, these may be included in a more extensive review paper that is currently in preparation. Therefore, the paper will start with HCCI combustion control through the charge reactivity and mixture stratification, then both the reactivity and stratification are applied to optimize the combustion process using dual-fuel compound combustion concepts (thermo-atmosphere combustion and RCCI/HPCC), and finally the combustion mode design fueled with dual-fuel strategy will be discussed.

\section{Experimental Setup and Instruments}

Two modified single-cylinder heavy-duty diesel engines and one four-cylinder light-duty diesel engine were used to explore the effects of different combustion modes controlled by both mixture stratification and charge reactivity. The specifications of these three engines are listed in Table 1, wherein engine A was used to study the charge reactivity and mixture stratifications controlled HCCI combustion and the thermal-atmosphere controlled compound combustion modes, engine $\mathrm{B}$ was used to investigate the RCCI/HPCC combustion concepts and the dual-fuel combustion control strategies, and engine $\mathrm{C}$ was used to explore the combustion mode design with dual-fuel strategy based on the previous results.

Independent intake and exhaust systems with intake pressure/ temperature and EGR rate control capabilities were setup for these two single-cylinder engines (Engines A and B). As for the multi-cylinder engine, both high pressure and low pressure EGR systems were installed to achieve the effective control of EGR and boost pressure together with turbocharger optimization. Two port injectors were mounted on the intake manifold and one DI injector was mounted on the cylinder head for engine A, all were controlled by separate electronic control units (ECU), with both

TABLE 1 | Engine specifications (Yao et al., 2007c; Yang et al., 2012; Tong et al., 2013).

\begin{tabular}{lccc}
\hline & Engine A & Engine B & Engine C \\
\hline Bore $\times$ stroke $(\mathrm{mm})$ & $115 \times 115$ & $105 \times 125$ & $96 \times 103$ \\
Displacement (L) & 1.2 & 1.081 & 2.98 \\
Compression ratio & 17.0 & 16.0 & $17.5 / 14.0$ \\
IVC timing (CA ATDC) & -135.0 & -133.0 & -130.0 \\
EVO timing (CA ATDC) & 125.0 & 125.0 & 126.0 \\
Number of valves $(-)$ & 4 & 4 & 2 \\
Swirl ratio $(-)$ & 2 & 1.6 & 1.8 \\
DI injector holes $(-)$ & 7 & 8 & 7 \\
DI cone angle $\left({ }^{\circ}\right)$ & 152 & 150 & 150 \\
DI nozzle diameter $(\mathrm{mm})$ & - & 0.15 & - \\
Port injector holes $(-)$ & - & 4 & 4 \\
Port cone angle $\left({ }^{\circ}\right)$ & - & 15.0 & 15.0
\end{tabular}

injection quantity and timing adjustable. As for engines B and $\mathrm{C}$, the port injector and DI injector were mounted on the intake manifold and cylinder head, respectively, to deliver the fuels into the chamber. The premixed charge reactivity and mixture stratification can be flexibly controlled in this manner according to the operating conditions and control strategies. For all three engines, in-cylinder pressures were measured with pressure transducers which were fitted flush with the wall of the cylinder heads and connected via a charge amplifiers to the data acquisition boards in computers. The shaft encoders had resolutions of either $0.2^{\circ}$ or $0.5^{\circ} \mathrm{CA}$. In-cylinder pressure traces were averaged for 50 or 100 cycles for each operating point, and then the heat release rate (HRR) and PPRR were calculated by combustion analysis software packages. The exhaust gas was measured using the Horiba MEXA-7100DEGR exhaust analyzer, which measures UHC by a method of hydrogen flame ionization (FID), CO, and $\mathrm{CO}_{2}$ by non-dispersive infra-red (NDIR) method and NOx using a chemiluminescent NOx analyzer (CLA). The soot emission was measured with an AVL 415S filter smoke meter. Throughout this study, the criterion of the PPRR is $1.0 \mathrm{MPa} / \mathrm{CA}$ degree. If PPRR exceeds this value, the engine usually works violently, the noise becomes unacceptable.

The energy balance analysis was conducted using the GT-Power package. The experimentally derived HRRs and exhaust temperatures (the temperature measurement point is $220 \mathrm{~mm}$ downstream the exhaust valves) have been used as the inputs to validate the simulation model. Validation results show that the agreements of exhaust gas temperatures between the experiments and predictions from simulations are reasonably good. In the calculations, the first law of thermodynamic can be expressed as the following equation:

$$
\begin{aligned}
Q_{\mathrm{f}} & =\oint P \mathrm{dv}+Q_{\mathrm{w}}+\left(Q_{\mathrm{ex}}-Q_{\mathrm{in}}\right)+Q_{\text {comb.loss }} \\
& =P \mathrm{dv}+Q_{\text {wall }}+Q_{\text {comb.loss }}+\Delta H
\end{aligned}
$$

wherein $Q_{\mathrm{f}}$ is the total energy contained in the fuel, $\oint P \mathrm{dv}$ is the indicated power, $Q_{w}$ is the heat transfer loss, $\Delta H$ is the exhaust loss, and $Q_{\text {comb.loss }}$ is the incomplete combustion loss. The indicated engine power can be derived from the measured cylinder pressures, the heat transfer loss was calculated using the Woschini GT model in the GT-Power package, the exhaust loss was obtained from the enthalpy difference between the intake and exhaust gas (assuming the combustion chamber to be a constant pressure system), and the incomplete combustion loss was calculated based on the measured concentrations of CO, UHC, and $\mathrm{H}_{2}$. Through this equation, the energy flow distributions of various combustion concepts can then be obtained.

\section{Charge Reactivity Controlled HCCI Combustion}

\section{Single Fuel $\mathrm{HCCl}$}

In the single fuel HCCI mode, the premixed homogeneous charge can be prepared by either port injection or early DI. For diesel HCCI, relatively high intake temperature was required to ensure the evaporation of diesel fuel with low volatility and high viscosity 
to ensure homogeneous charge. DME, which has quite similar ignitability (cetane number $\approx 55$ ) compared to conventional diesel fuel, but is much easier to evaporate, was then chosen as one of the primary fuels to study the HCCI combustion control strategy in the authors' group (Yao and Qin, 2004). In addition, the DME oxidation mechanism was also much simpler than diesel fuel, which favors the development of reduced chemical kinetic mechanisms for the computational fluid dynamic (CFD) simulations.

Yao et al. (2005b) and Huang et al. (2009) conducted multidimensional modeling studies on the oxidation process of single high cetane number DME fuel in a single-cylinder HCCI engine (Engine A in Table 1). It was found that the HCCI combustion of DME is quite similar to that of diesel fuel, which exhibits a two-stage heat release process. The DME concentration has almost no effect on the LTR but mainly affects the HTR. Theoretically, the mixture and temperature distributions should be perfectly homogeneous. However, in real applications, both temperature and concentration gradients exist in HCCI combustion process due to the mixture preparation, wall heat transfer, and turbulence interaction. It was found that the LTRs and HTRs do not occur simultaneously throughout the cylinder in the simulations. The LTRs are initiated near the piston surface and squish region, and the HTRs are initiated in the combustion chamber core zone and squish region. Therefore, throughout the DME HCCI combustion process, the in-cylinder temperature distribution undergoes a process from inhomogeneity to homogeneity. The unburned fuel and $\mathrm{CH}_{2} \mathrm{O}$ account for the majority of UHC emission. However, since the cetane number of DME is comparable to that of diesel, stable HCCI combustion can only be operated under fairly low load conditions, mainly limited by the PPRR.

In addition to the HCCI combustion fueled with DME, the effects of different high octane number fuels, including the primary reference fuels (mixtures of $n$-heptane and iso-octane), unleaded commercial gasoline, and mixtures of PRF and ethanol, on the combustion and emissions of HCCI engine were also experimentally investigated under different intake pressure conditions (Engine A in Table 1) (Liu et al., 2008, 2009; Yao et al., 2008). It was found that the ignition timing advances and in-cylinder pressure increases as the intake pressure increases. The effect of fuel properties on the HCCI combustion process depends upon the operating conditions. Gasoline is more reactive at low intake pressure while PRF is more reactive at high intake pressure, and the effects of PRF octane number on auto-ignition become smaller as the inlet pressure increases. Figure 1 shows the effects of boost pressure and research octane number (RON) on HCCI operating ranges (Liu et al., 2008). It is seen that the upper and lower loads can be extended by increasing the intake pressure. The maximum achievable load of gasoline is higher than that of PRF with the cases of supercharging. This can be attributed to the reason that more sensitive fuels (larger difference between RON and motor octane number (MON), such as gasoline) are likely to allow an HCCI engine to operate over a wider load range at given speed than less sensitive fuels. In addition, although not shown here, the PRF octane number has little effect on the $\mathrm{UHC}, \mathrm{CO}$, and NOx emissions when supercharging is employed.
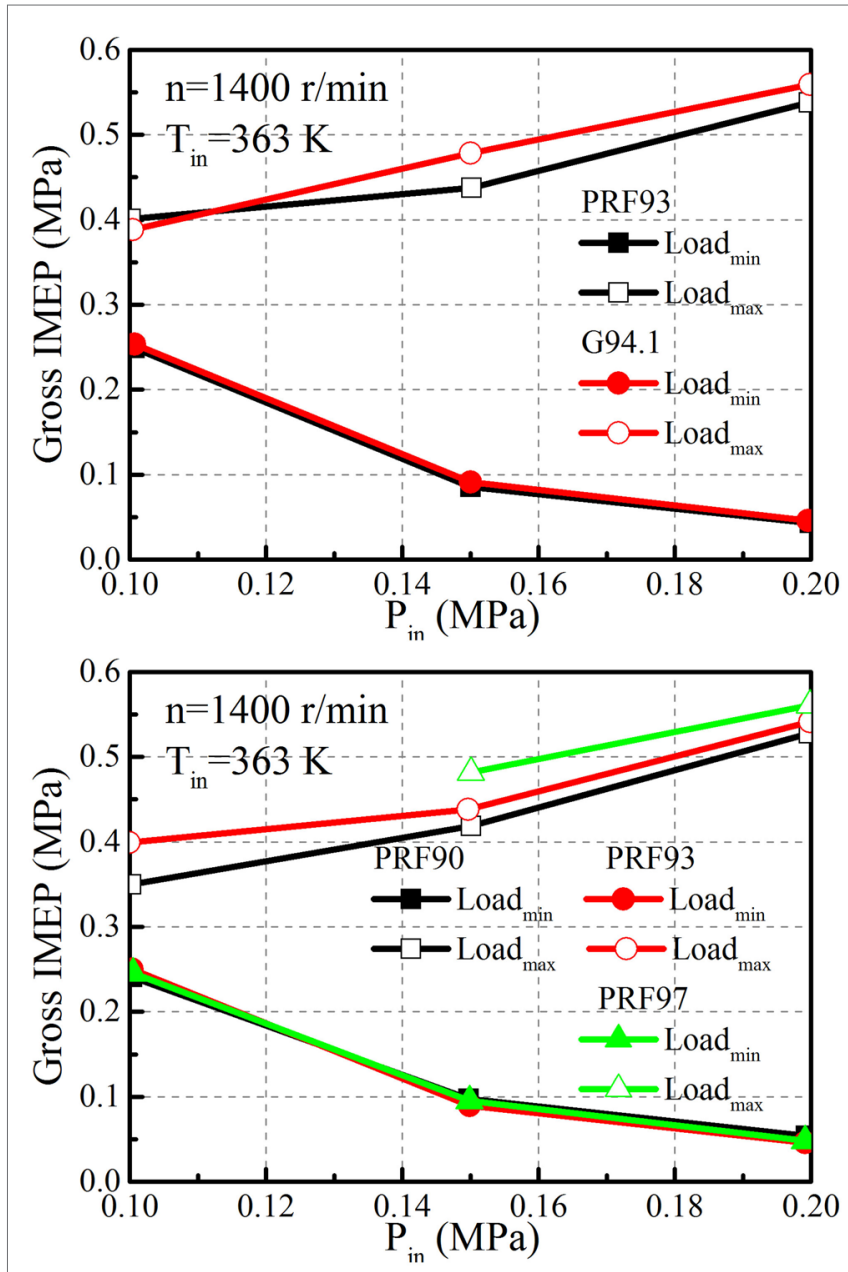

FIGURE 1 | Effects of boost pressure and RON on single fuel $\mathrm{HCCl}$ operating ranges.

Nevertheless, the UHC and CO emissions of gasoline are higher than those of PRF with supercharging.

\section{Dual-Fuel HCCI}

Since single fuel cannot meet the reactivity requirements under different operating conditions in HCCI operation, thus the dual-fuel HCCI combustion concept has been proposed by port injecting two fuels with different reactivities, such as $n$-heptane and iso-octane (Yao et al., 2004, 2007c), or DME and methanol/ methane (Zheng et al., 2004; Yao et al., 2005a,b,c, 2006, 2007b,d). In this case, the overall charge reactivity can be effectively adjusted by changing the ratio between two fuels through two port injectors under different conditions, i.e., high overall reactivity under low load conditions to promote the auto-ignition and low overall reactivity under high load conditions to suppress the auto-ignition.

The influence of PRF fuel's octane number on the combustion characteristics, performance, and emissions of HCCI engine has been investigated by Yao et al. (2007c) (Engine A in Table 1). Five different PRF fuels, including the PRF0 ( $n$-heptane), PRF40 
(60\% $n$-heptane and 40\% iso-octane), PRF60, PRF80, and PRF90, were used in the experiments. The engine was running at $1400 \mathrm{r} /$ min. Figure 2 shows the effects of PRF number on the HCCI combustion characteristics, indicating thermal efficiency (ITE) and operating range. It is seen that the octane number of PRF fuel largely affects the HCCI combustion process. With the increase of the octane number, the ignition timing delays, the combustion rate decreases, the combustion duration prolongs, and the cylinder pressure decreases. In addition, increasing RON retards both the LTR and HTR, and prolongs the negative temperature coefficient (NTC) phase.

It is apparent that the fuels with different octane numbers exhibit different HCCI operating ranges (Figure 2B). Fuel with low RON can operate at low indicated mean effective pressure (IMEP) conditions, and high RON fuel can realize much higher IMEP operations. Correspondingly, the operating range changes significantly for different octane number fuels. The maximum load can be extended to 0.54 MPa IMEP when PRF90 fuel was used. It is clearly shown in Figure $\mathbf{2 C}$ that there exists an optimum RON that could achieve the highest ITE at different engine loads (indicated by the variation of air/fuel ratio).

In addition to the PRF fuel, the dual-fuel HCCI combustion was also studied using DME/methanol and DME/methane by Zheng et al. (2004) and Yao et al. (2005c). It was found that the effects of DME ratio on DME/Methanol HCCI combustion are quite similar to those of the PRF HCCI operation. The auto-ignition timing and combustion phasing can be effectively adjusted by changing the premixed ratio between low RON DME and high RON methanol, indicating the successful manipulations of the overall charge reactivity. By adopting DME/methanol dual-fuel, the HCCI operating region can be largely extended, the maximum IMEP can reach $0.77 \mathrm{MPa}$ at low engine speeds.

The HCCI combustion fueled with DME and compressed natural gas (CNG) was also investigated in the same single-cylinder diesel engine by Yao et al. (2005c) (Engine A in Table 1). Similar to the PRF and DME/methanol dual-fuel HCCI combustion, adjustment of the proportion of DME and CNG is an effective technic to control the HCCI combustion process and to extend the HCCI operating range. The HCCI process of DME/CNG dual-fuel is also characterized by a two-stage heat release process, and the second heat release begins near top dead center (TDC). Their later numerical study indicated that the first stage of heat release mainly comes from the DME oxidation through an HTR, and the second stage of heat release mainly comes from the methane oxidation.

Figure 3 shows the maximum loads that can be achieved using different fuel strategies. Due to the high cetane number, the maximum load that can be obtained with single DME fuel was around $0.3 \mathrm{MPa}$ IMEP. When switched to dual-fuel strategy, the upper load limit can be extended to about $0.65 \mathrm{MPa}$ IMEP with $\mathrm{DME} / \mathrm{methane}$ dual-fuel, and the load can be further increased up to $0.77 \mathrm{MPa}$ IMEP when DME/methanol was used. This result clearly shows that the stable HCCI operation range can be effectively extended by adopting the dual-fuel strategy, and the higher the octane number difference between the two fuels, the wider the operating range that can be achieved.

The effects of cooled EGR on the DME/methanol dual-fuel HCCI combustion, performance, and emissions have also been
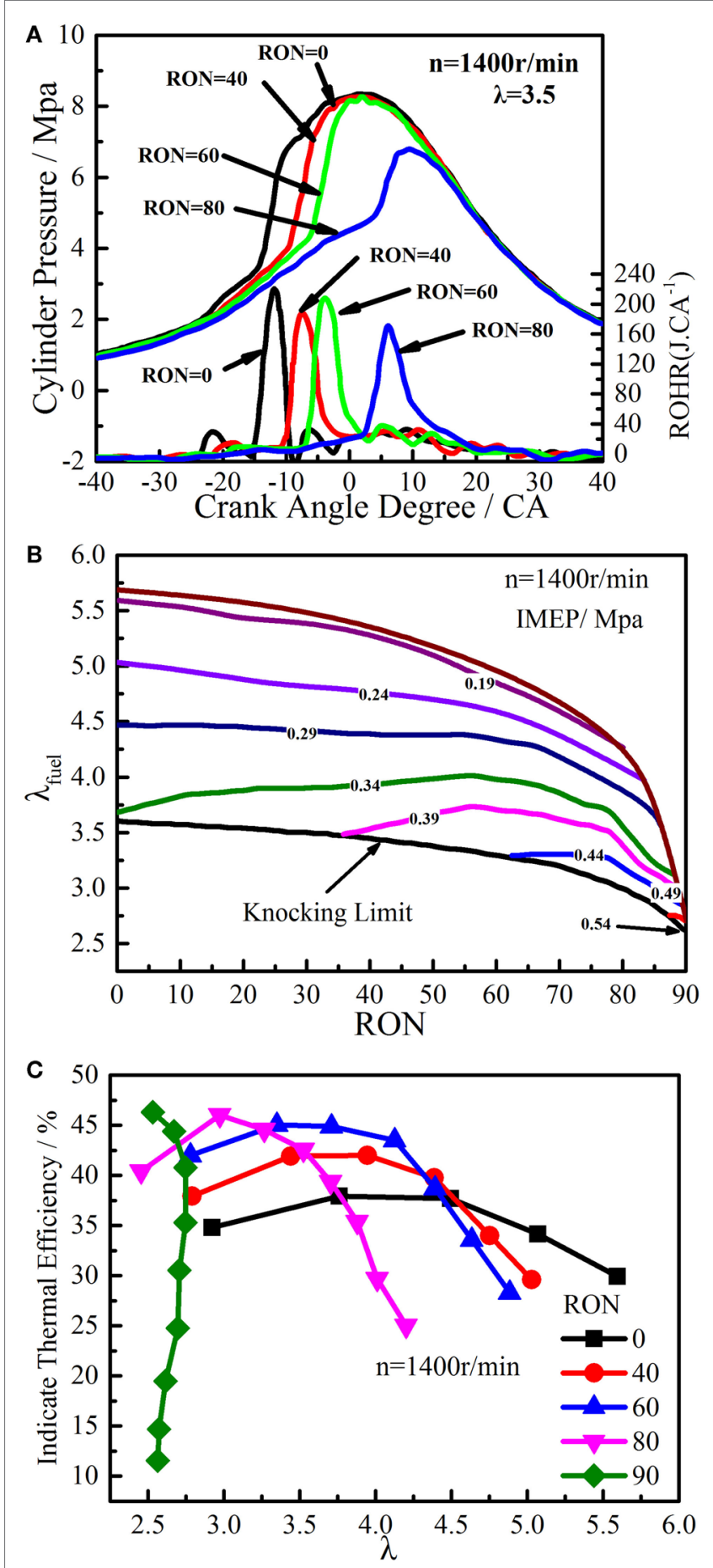

FIGURE 2 | (A) The effects of PRF RON on in-cylinder pressure and heat release rate, (B) the effects of PRF RON on indicated thermal efficiency, (C) the effects of PRF RON on operating load range.

studied by Yao et al. (2005a). Due to the dilution and heat capacity effects of cooled EGR, with fixed DME ratio (constant charge reactivity), both the auto-ignition timing and combustion phasing can be retarded, and the peak in-cylinder pressure and HRR can be reduced by increasing EGR. Figure 4 shows the effects 


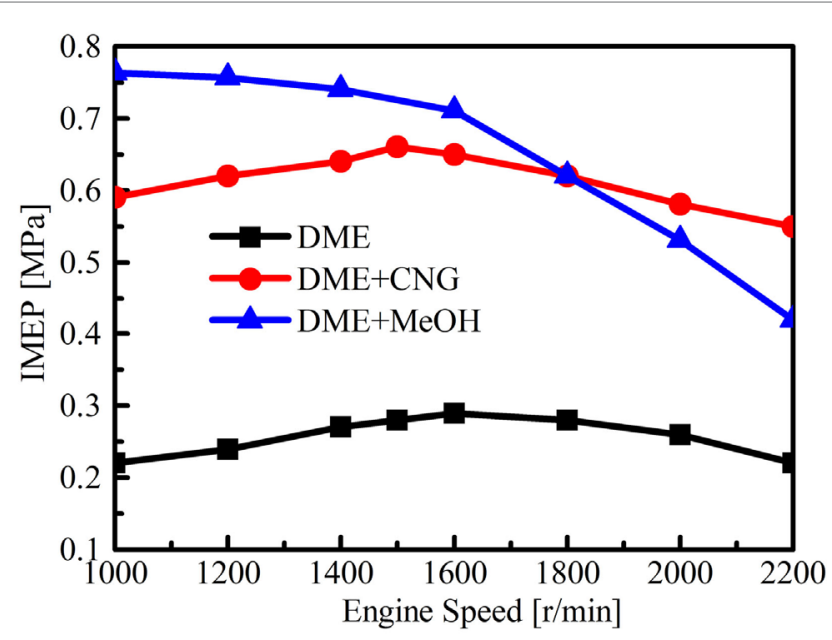

FIGURE 3 | Maximum operating loads that can be achieved using different fuel strategies in dual-fuel $\mathrm{HCCl}$ operation.

of EGR on the combustion, operation range, and ITE in DME/ methanol dual-fuel HCCI operation. As shown in Figure 4A, the DME percentage range in normal combustion region without EGR is relatively narrow at high loads. With the increase of EGR, the region between the partial burn limit and the knocking limit becomes wider. This indicates that the ignition timing and combustion reaction rate of HCCI can be controlled effectively by increasing EGR. The results in Figure 4B indicate that EGR rate can enlarge the controllable HCCI operating region, but it has little effect on the maximum load of HCCI engine fueled with DME/methanol dual-fuels. Figure 4C suggests that, in normal combustion region, optimized HCCI combustion with high ITE can be achieved by adopting large DME percentage and high EGR in this dual-fuel combustion concept.

\section{Charge Reactivity and Stratification Controlled Combustion}

\section{Single Fuel Stratification Controlled $\mathrm{HCCl}$}

As mentioned in the introduction, the charge stratification has been regarded as a potential mechanism for controlling HCCI combustion. Both experimental and numerical studies have been conducted to explore the charge stratification to control the HCCI combustion by port injection and DI of the same $n$-heptane fuel (Yao and Zheng, 2007; Zheng and Yao, 2007). The stratification can be altered by changing the ratio between the port and DI fuel mass and also the DI timing. The engine was running at $1400 \mathrm{r} / \mathrm{min}$, with an overall equivalence ratio of 0.3 (Engine A in Table 1).

Figure 5 shows the effects of DI ratio and timing on the combustion process. The in-cylinder pressure from the pure HCCI combustion under the same condition is also shown in the plots with dashed lines. It is seen in Figure 5 that both the DI ratio and timing affect the combustion process. With fixed DI timing, a higher DI ratio indicates a stronger charge stratification, which is shown to be helpful for PPRR reduction compare to pure HCCI
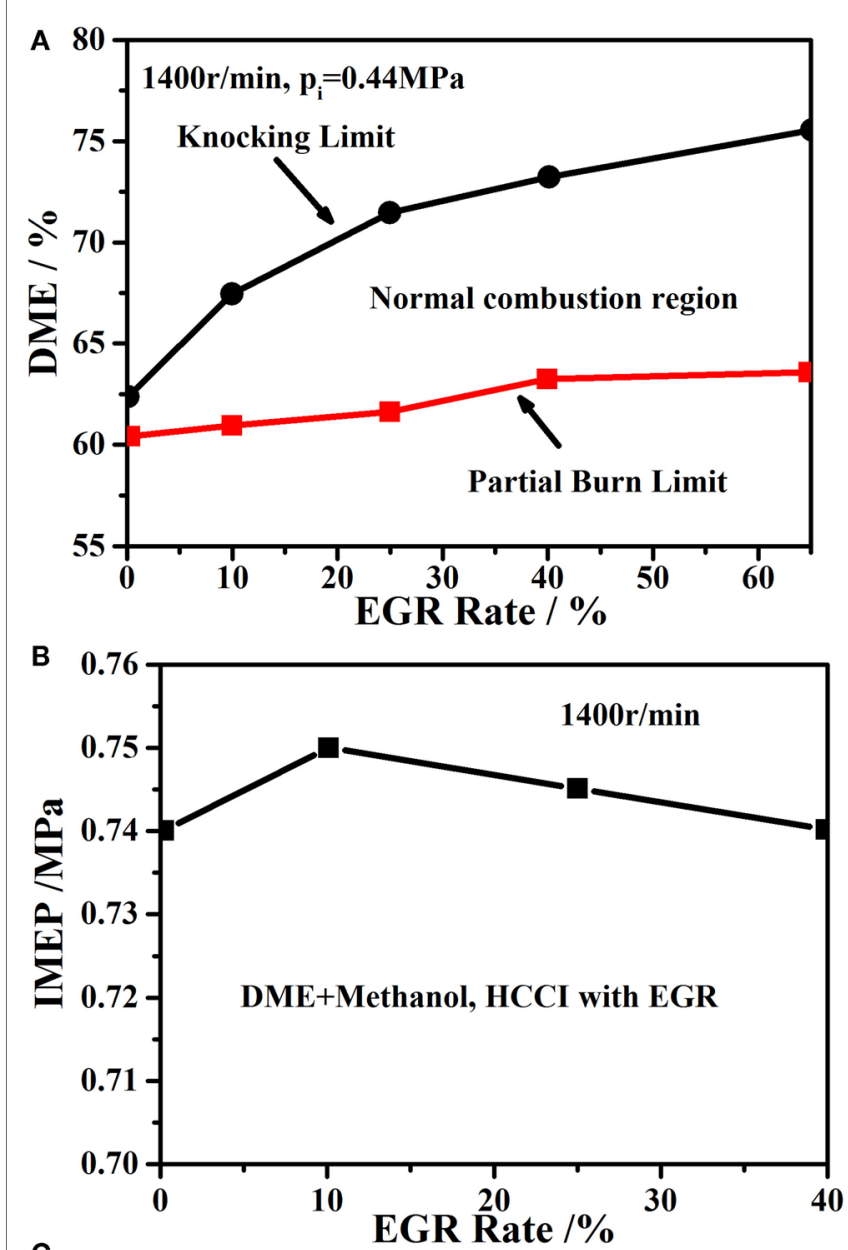

C

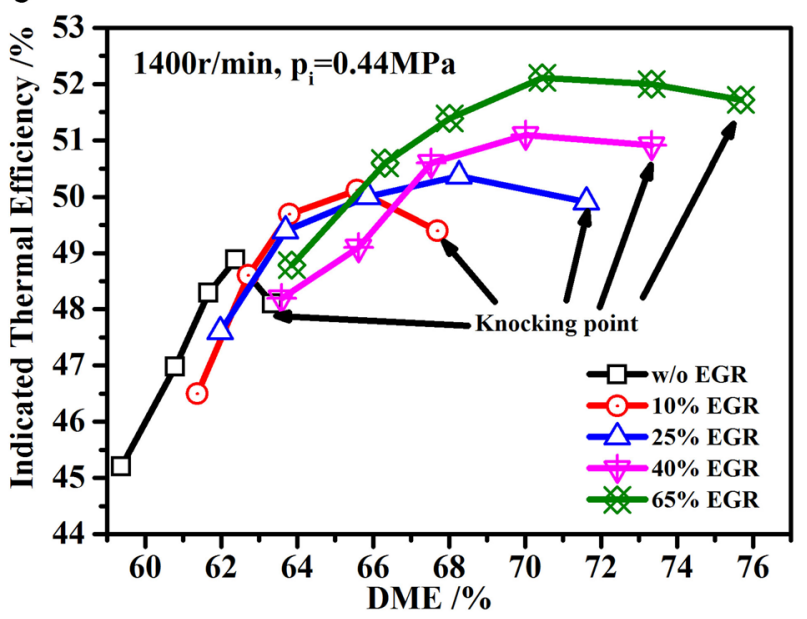

FIGURE 4 | (A) The effects of EGR on operating load range, (B) the effects of EGR on the maximum loads, (C) the effects of EGR on indicated thermal efficiency.

combustion. With the increase of DI ratio, the onset of the HTR advances, the PPRR and UHC emissions decrease, and CO emissions increase. The effects of injection timing on the combustion and emissions have close relation to the DI ratio. A small DI ratio has limited effects on the in-cylinder pressure and emissions; 

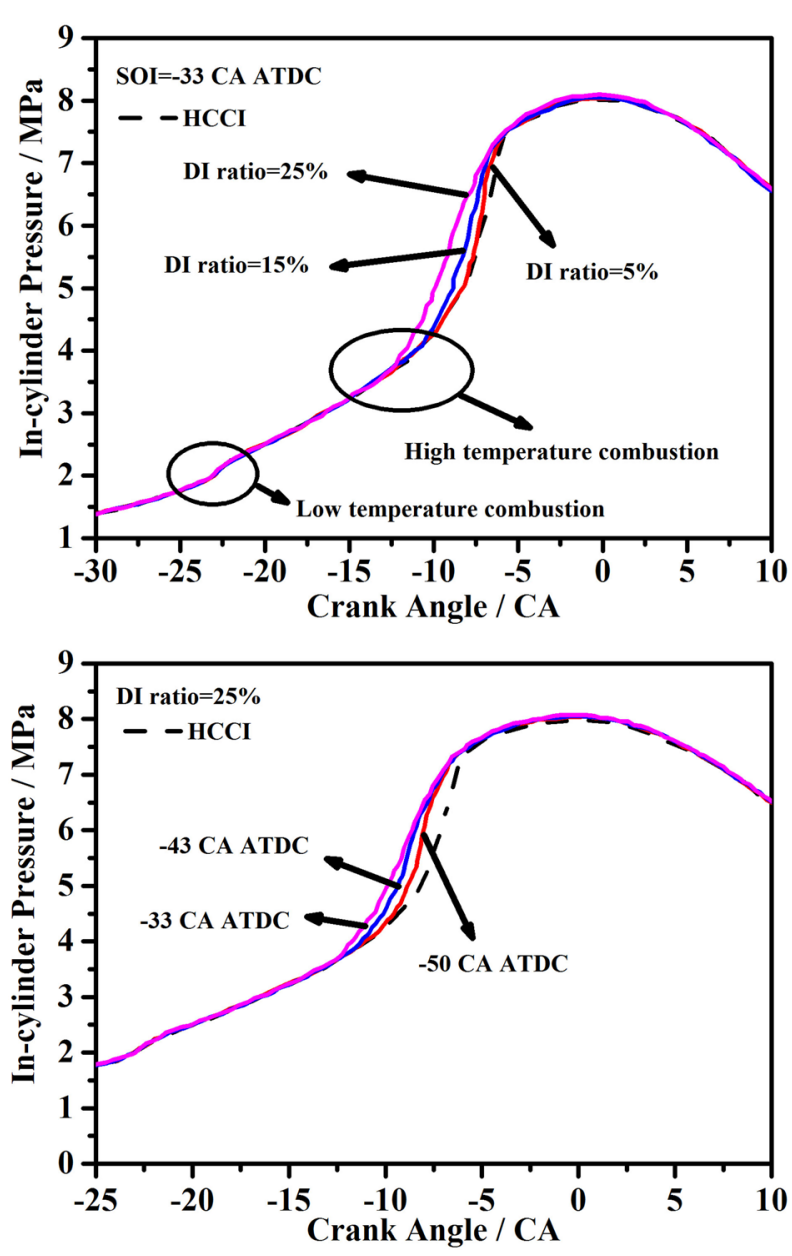

FIGURE 5 | Effects of DI ratio and timing on combustion process in charge stratification combustion mode.

with larger DI ratio, the onset of the HTR advances and the PPRR decreases with retarded DI timing. However, the major concerns for this single fuel combustion mode were the NOx and $\mathrm{CO}$ emissions. The NOx emissions increase with the increase of DI ratio and the retarding of the injection timing in the condition of present premixed/direct-injected fuel combustion, which suggests that the NOx emissions increase with the stratification degree because of the existence of high equivalence ratio and high temperature regions introduced by the DI spray event.

In Zheng et al.'s study (Zheng and Yao, 2009), seven different imposed stratifications have been introduced according to the position of the maximal local fuel/air equivalence ratio in the cylinder at intake valve close (IVC) for two different equivalence ratios $(0.2$ and 0.264$)$ at $1400 \mathrm{r} / \mathrm{min}$. The results show that the charge stratification results in stratification of the in-cylinder temperature, the charge stratified combustion has the potential of overcoming the problems of HCCI combustion (too rapid combustion, high CO and UHC emissions).

In addition, both charge and thermal stratifications have also been studied using optical diagnostic technics to achieve HCCI combustion control. Liu et al. (2010, 2011) used chemiluminescence imaging technic to study the effects of different port fuel injection strategies and thermal stratifications on HCCI combustion in a single-cylinder optical diesel engine. The results show that under lower intake temperature condition, the port fuel injection strategies have a larger effect on the HCCI combustion process. The combustion reaction rate can be reduced with larger local temperature stratification. As a result, the PPRR can be reduced and the HCCI operating range can be extended. Different thermal stratifications can also be adjusted by changing the piston bowl geometries (Liu et al., 2011). It was found that different combustion chamber geometries generated different turbulence intensity, which has the potential to modulate the combustion process in HCCI engines.

\section{Dual-Fuel Thermo-Atmosphere Controlled Compound Combustion}

As discussed above, both the reactivity and charge stratifications affect the HCCI combustion process, which provides valid measures to achieve HCCI combustion control. In the authors' previous study, DME/methanol dual-fuel HCCI has been demonstrated to be able to regain the control of HCCI combustion and to extend the HCCI operating range (Yao et al., 2007d). Based on these studies, a thermal-atmosphere controlled compound combustion concept has been studied by port injection of high cetane number fuel and DI of high octane number fuel (Yao et al., 2007a; Chen et al., 2009). In this way, the premixed high reactivity DME/air mixture provides favorable thermal conditions for the auto-ignition and oxidation of directly injected methanol. Optimal combustion characteristics can be achieved at different operating conditions by adjusting the premixed DME ratio and DI methanol injection timing.

Figure 6 shows the effects of the methanol DI timing on in-cylinder pressures and HRR in DME/methanol thermal-atmosphere controlled compound combustion mode. For later methanol injection, the combustion mode is the HCCI combustion of DME and the low-temperature diffusion combustion of methanol. As the injection timing is advanced, due to the improvement in homogeneity, the peak pressure and the second peak of HRR increase significantly. Further increase of the methanol fuel mass in this case would result in significant increase in PPRR, even knock. Therefore, in this dual-fuel compound combustion concept, late injection is preferred to suppress the pressure rise rate if more DI methanol fuel is used. Further advancing the injection timing with small methanol mass would result in partial burning or miss fire, thus a higher DME premixed ratio is required to ensure the ignition and combustion stability under this condition. The above results also indicate that the DI methanol fuel mass largely affects the choice of methanol injection strategy.

Figure 7 shows the effects of methanol injection timing and concentration on the IMEP and NOx emission. It can be seen that IMEP increases with increased methanol concentrations. IMEP first increases and then decreases as the injection timing advances with low methanol concentrations, whereas IMEP increases monotonically with higher methanol concentrations. Later injection results in slightly lower IMEP due to the later autoignition and longer combustion duration of methanol diffusion 

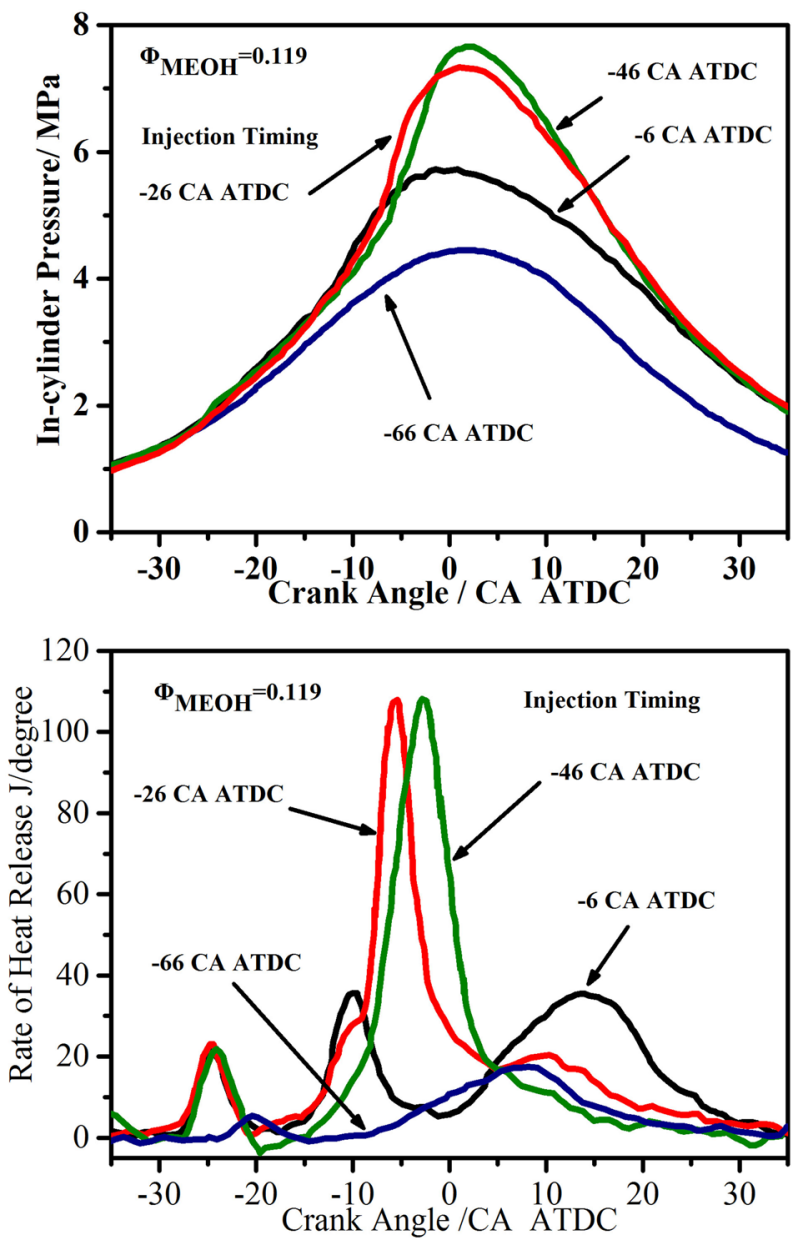

FIGURE 6 | Effects of injection timing on (A) in-cylinder pressure and (B) rate of heat release in thermal-atmosphere controlled combustion mode.

combustion. The auto-ignition timing and combustion phasing are more appropriate as the injection timing advances, thus IMEP increases accordingly. IMEP decreases sharply at low methanol concentrations due to miss fire with advanced methanol injection timing. NOx emission first increases and then decreases with the advance of injection timing. With increasing methanol concentration, NOx emissions of earlier injection timing increases sharply due to the knock combustion, whereas NOx emissions can be effectively reduced through methanol injection strategy optimization. In addition, $\mathrm{UHC}$ and $\mathrm{CO}$ emissions depict similar trends in this compound combustion concept, that both emissions first decrease and then increase as the injection timing advances, and both emissions decrease as the methanol concentration increases.

To conclude, it is seen that the engine can be operated at high loads with this thermal-atmosphere controlled compound combustion mode. Low CO and UHC emissions can be obtained by controlling the DI timing and methanol concentration, while NOx emission can also be controlled through methanol injection strategy optimization.

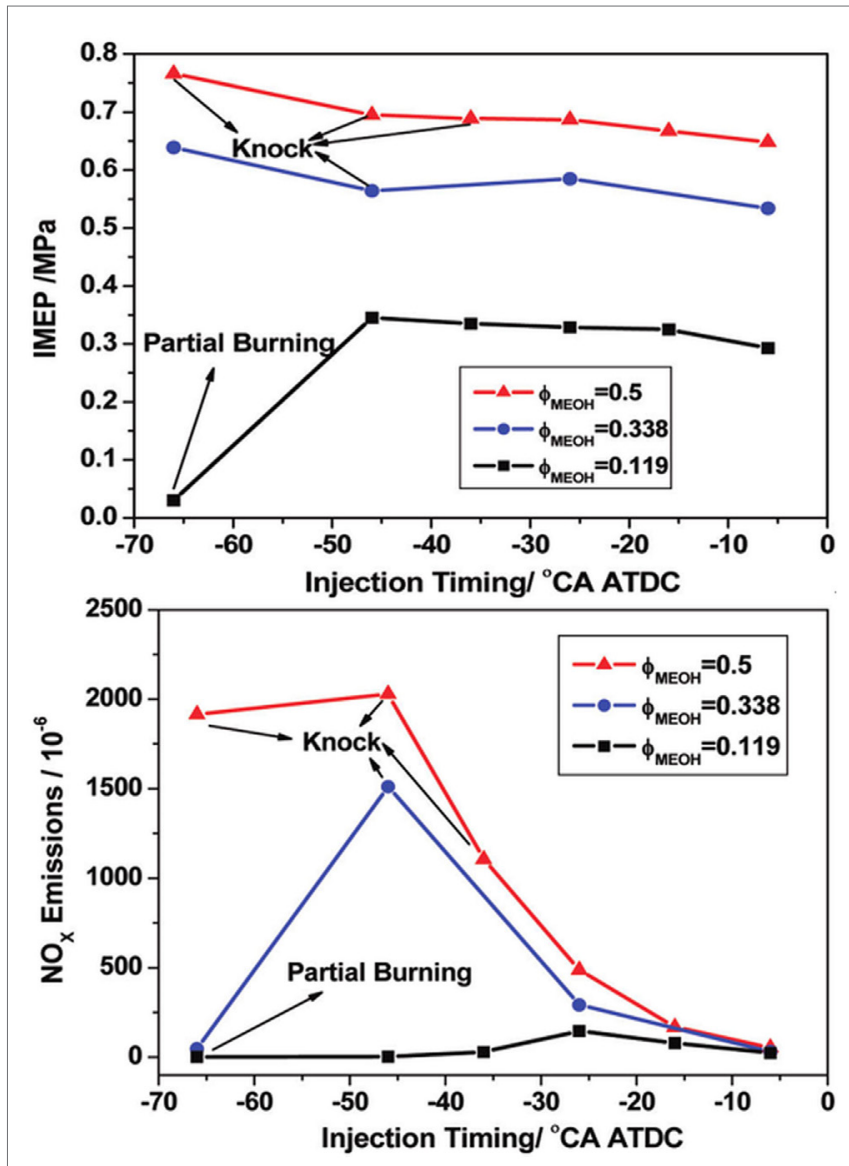

FIGURE 7 | Effects of methanol injection timing and concentration on IMEP and NOx emission in thermal-atmosphere controlled combustion mode.

\section{Dual-Fuel RCCI/HPCC Combustion}

In contrast to the thermal-atmosphere controlled combustion mode, in the dual-fuel RCCI/HPCC combustion concept, a high octane number fuel was introduced through port injection to form premixed homogeneous charge, while a high cetane number fuel was directly injected to the combustion chamber to serve as the ignition source. In this case, due to the quite different reactivity between the premixed and DI fuels, both reactivity and charge stratifications exist in the combustion chamber. The auto-ignition and combustion starts at the regions with high reactivity and equivalence ratio, and gradually spread to the rest of the chamber. The auto-ignition timing can be controlled by the DI timing, and due to the gradients in both reactivity and concentration, the combustion reaction rate and combustion duration can be well controlled by the degree of stratifications. In this approach, both the ignition timing and combustion phasing, as well as pressure rise rate, can be effectively manipulated by the coupling control of the DI strategy and splitting ratio better premixed and DI fuels. This combustion mode can be regarded as quasi-HCCI if late DI timing was used. Reitz et al. at the Engine Research Center in University of Wisconsin-Madison have conducted pioneering and insight investigations on the development of this RCCI 
combustion concept (Reitz and Duraisamy, 2015). It has been demonstrated to be highly efficient, and is a promising strategy to meet current and future emissions regulations without relying on NOx and soot after-treatment, and the maximum operation load can be expanded up to 14.6 bar IMEP at $1300 \mathrm{r} / \mathrm{min}$ on a heavy-duty diesel engine through experiments.

\section{Effects of Combustion Mode on Combustion and Emissions}

In order to demonstrate the capability of the dual-fuel RCCI/ HPCC mode, first the effects of different combustion modes on engine performance and emissions have been investigated experimentally on a modified single-cylinder diesel engine (Engine B in Table 1) (Yang et al., 2012). The engine was running at $1500 \mathrm{r} / \mathrm{min}$, with constant cyclic fuel mass of $50.0 \mathrm{mg}$ equivalent diesel. The CA50 timing was kept at 8.0 CA after top dead center (ATDC), and single injection strategy was used for the DI diesel fuel in these comparisons.

It is seen in Figure 8A that the same CA50 timing can be obtained by either early or late injection of the DI fuel, thus three different combustion modes have been tested, including the conventional low-temperature combustion fueled with blends of $20 \%$ diesel and $80 \%$ gasoline, the early injection HPCC (E-HPCC) and late injection HPCC (L-HPCC) with port injection of $80 \%$ gasoline and DI of $20 \%$ diesel. Figure $\mathbf{8 B}$ shows the required injection timing to keep CA50 at 8.0 CA ATDC as a function of EGR. The charge becomes more homogeneous if the early injection was used due to the more available mixing time, thus the overall reactivity can be increased; while the charge stratification increases if the late injection strategy was used. Figure 8C shows the comparisons of energy balance analysis among three modes. It is seen that the LTC mode has the highest exhaust loss, but this can be recovered by turbocharger. In the L-HPCC mode, the combustion initially occurs in the center of the chamber, and then gradually spreads to the rest of the chamber, results in the lowest heat transfer loss. The combustion efficiency of LTC is higher than the other two combustion modes. Overall, the ITE of these three combustion modes are quite close, in spite of different mixture organization and heat release profiles. Figure 8D shows that near-zero soot emissions can be obtained with all these combustion modes. Ultra-low NOx can be obtained with E-HPCC mode, while the NOx emissions of L-HPCC and LTC can be dramatically reduced by EGR. Therefore, although more NOx was formed due to the existence of the late injection spray in the L-HPCC mode (which can be reduced by EGR), the lowest PPRR suggests that this mode has the potential to extend the stable combustion to high- and full-load conditions (Yang et al., 2014).
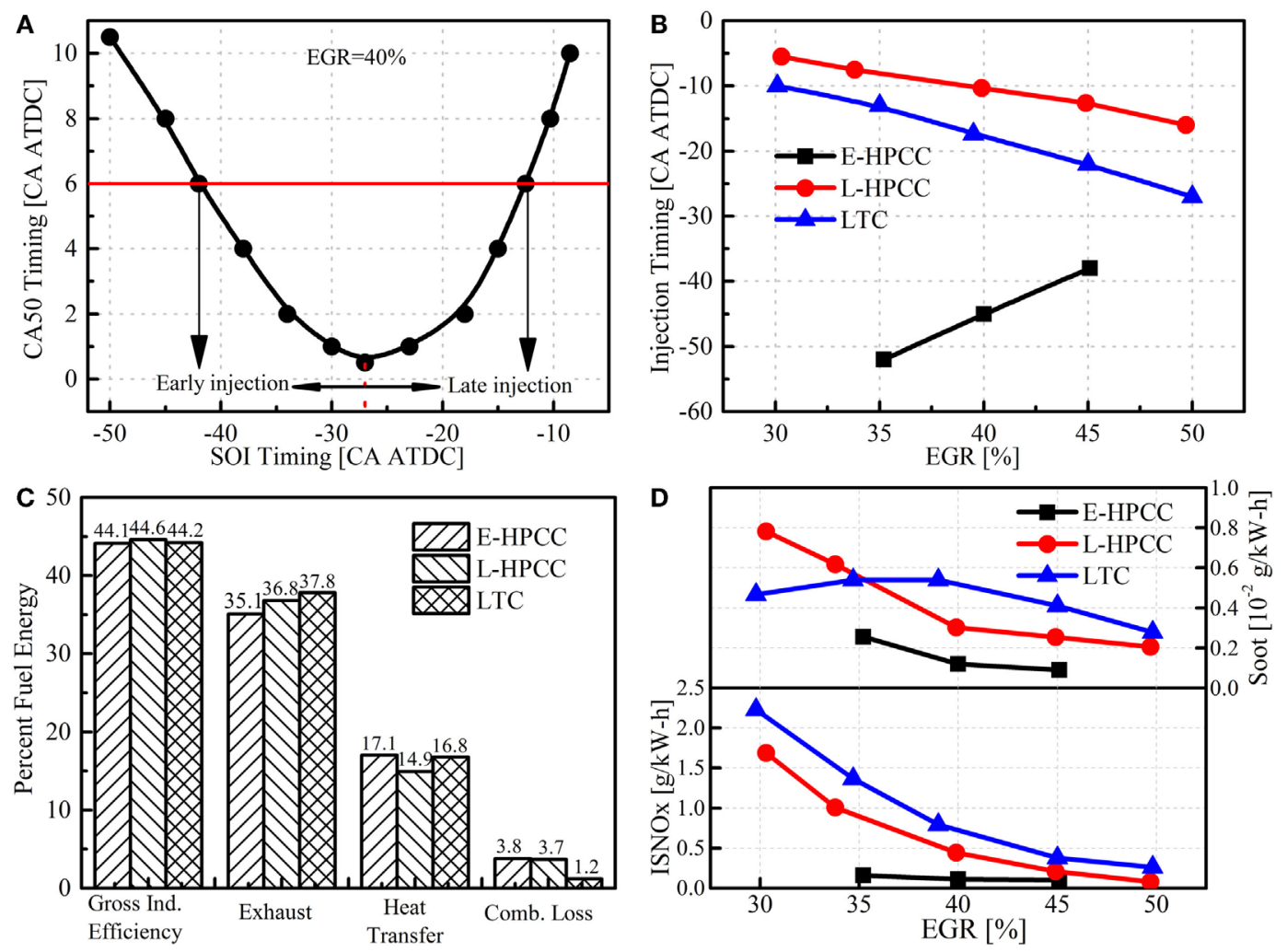

FIGURE 8 | Effect of SOI timing on CA50 timing in HPCC combustion (A), the required SOI timing as a function of EGR rate to keep CA50 at $8.0^{\circ}$ ATDC for the three combustion modes (B), the comparisons of energy flow analysis (C), and soot and NOx emissions (D) among LTC, L-HPCC, and E-HPCC modes. 
In addition, $n$-butanol/biodiesel dual-fuel HPCC combustion has also been studied by Liu et al. (2014). n-Butanol was injected into the intake manifold to form premixed homogeneous charge, while the soybean biodiesel was directly injected into the cylinder to serve as the ignition source. Engine B in Table 1 was used in the experiments, and the engine load was around $0.95 \mathrm{MPa}$ IMEP (56\% load of the original engine), with total fuel mass of $60 \mathrm{mg}$ equivalent biodiesel. Similar to the gasoline/diesel dual-fuel combustion, E-HPCC and L-HPCC modes can also be classified with $n$-butanol/biodiesel dual-fuel, that the same CA50 can be achieved by either the early or late injection of biodiesel. Increasing the premixed ratios can retard the combustion phasing and reduce the pressure rise rate, while the ITE reduces by about $0.6 \%$ as increasing premixed ratio to $90 \%$. The early injection has lower NOx emissions compared to the late injection due to the lower combustion temperature. The soot emissions are comparable between early- and late injection strategies. With the increase of EGR, the NOx and soot emissions decrease, while the UHC and CO emissions increase. The ITE reduces by $1-2 \%$ as increasing EGR to $45 \%$. The successful operation of HPCC mode with $n$-butanol/biodiesel clearly suggests that in addition to the flexible combustion control, fuel flexibility is another advantage associates with this combustion mode.

\section{Injection Strategy Optimization in Dual-Fuel $\mathrm{RCCl} / \mathrm{HPCC}$ Combustion}

Further studies have been conducted to study the effects of injection strategy on the combustion, performance, and emissions in HPCC mode. In Ma et al.'s study (Ma et al., 2013), experiments have been conducted to optimize the combustion process by considering the gasoline/diesel ratio, diesel injection strategy, and EGR. Single- and double-injection strategies were employed in the experiments at $1500 \mathrm{r} / \mathrm{min}$ with cyclic fuel mass of $50 \mathrm{mg} /$ cycle total equivalent diesel. Parameters, including the first and second injection timings, diesel splitting ratio between two injections in double-injection strategy, and the premixed gasoline ratio, were studied and optimized in the experiments.

In the double-injection strategy, if the first start of injection (SOI1) timing is fixed, a same CA50 can be achieved by a late or an early second start of injection (SOI2) timing, thus the doubleinjection strategy can also be divided into L-SOI2 and E-SOI2 strategies as in the case of single injection (Figure 9A). In this double-injection strategy, the first injection fuel improves the mixture reactivity, more early injection, more homogeneous mixture. The injection timing of the second injection timing (SOI2) can be used to control the charge reactivity and stratification. Advanced SOI2 increases the charge reactivity and retarded SOI2
A

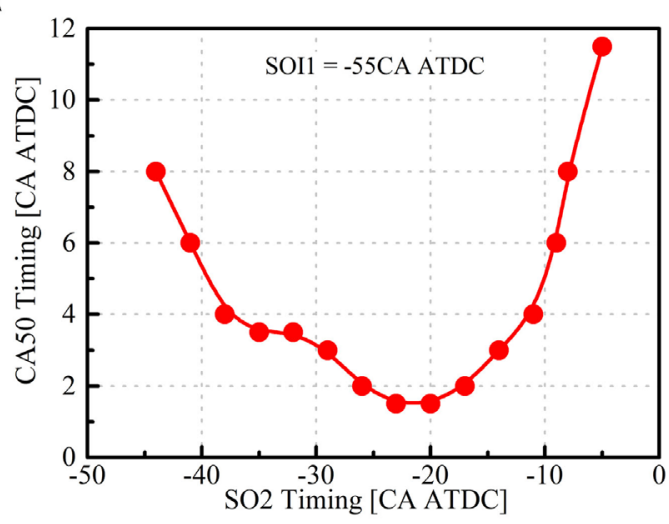

B

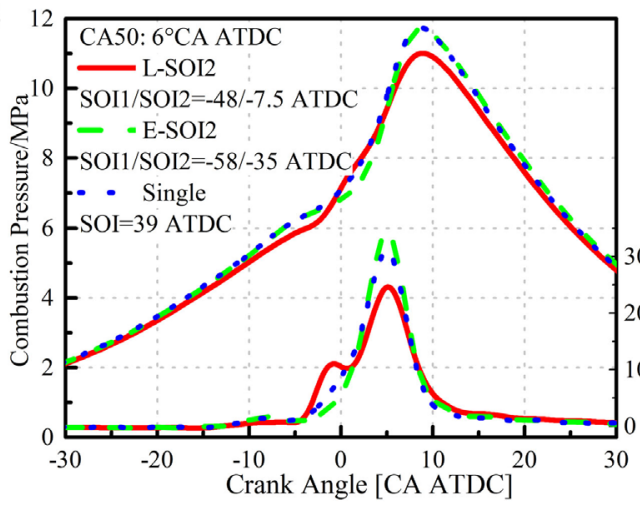

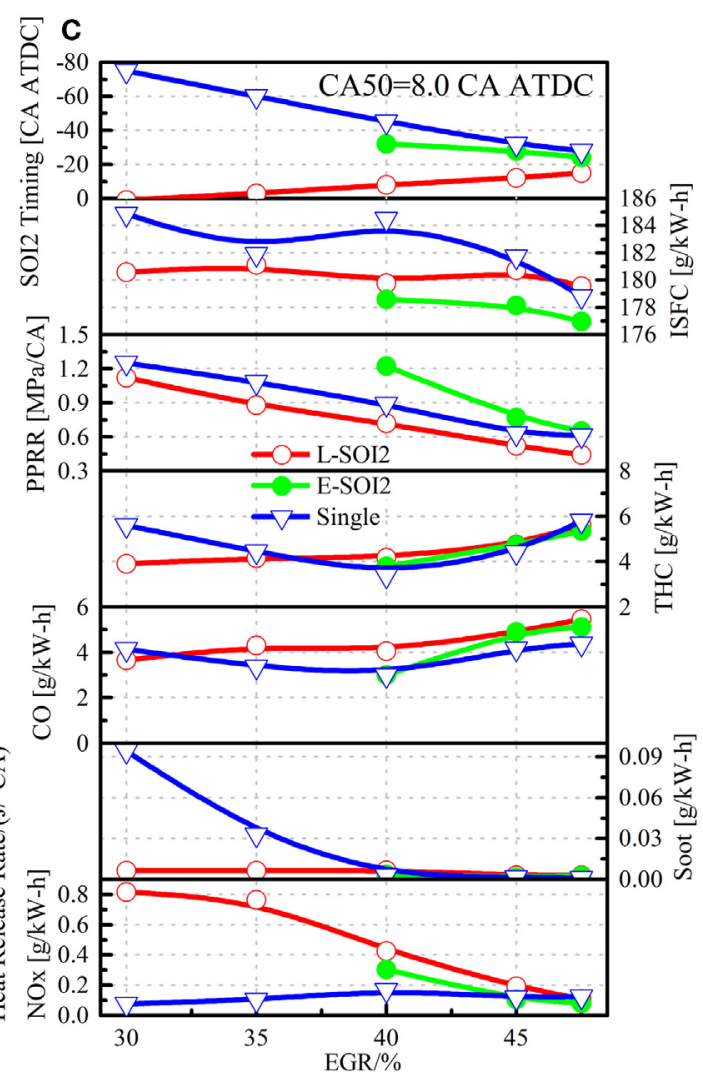

FIGURE 9 | Various comparisons among LTC, E-HPCC, and L-HPCC. (A), CA50 timing as a function of SOI2 timing. (B), comparison of cylinder pressure and HRR for three injection strategies at the same CA50 of 6 ATDC. (C), comparisons of three combustion modes in terms of SOI2 timing, PPRR, ISFC, and emissions as a function of EGR. 
increases the charge stratification, which eventually controls the auto-ignition and combustion events.

Figure 9B shows the comparisons of in-cylinder pressure and HRR among three injection strategies at the same CA50 timing of $6^{\circ}$ CA ATDC. The HRR changes from two-stage for L-SOI2 case to single stage for E-single and E-SOI2 strategies, which indicates that the combustion moves from partially diffusion controlled pattern to almost totally kinetically controlled pattern. Therefore, the characteristics of gasoline/diesel dual-fuel combustion mode can be well controlled by the injection strategies. Figure 9C shows the comparisons of three combustion modes in terms of SOI2 timing, PPRR, ISFC, and emissions as a function of EGR. It is seen that higher EGR is required to reduce the NOx emissions for L-SOI2 strategy due to the late injection timing. However, L-SOI2 could yield the lowest HRR and longest combustion duration, which is helpful for PPRR reduction. In addition, ultra-low soot emission can also be obtained with L-SOI2 strategy.

Since the L-SOI2 was found to be able to reduce the PPRR, thus this strategy was then used to further expand the operation range of the dual-fuel combustion concept. Table 2 shows the operating conditions for the experiments. In these tests, the SOI1 was fixed at $-55.0^{\circ} \mathrm{CA}$ ATDC, DI diesel fuel mass was increased from 8.0 to $12.0 \mathrm{mg} /$ cycle, and SOI2 was adjusted to maintain the CA50 timing at $8-9^{\circ} \mathrm{CA}$ ATDC at $45 \%$ EGR rate. The premixed gasoline fuel mass was gradually increased to increase the load (IMEP) until the prescribed criteria are violated, including the upper limits for NOx, soot, PPRR, and coefficient of variability (COV).

Figure 10 shows the major results for these experiments. For each diesel injection mass, the premixed gasoline mass can be increased as the DI injection pressure increases, thus the total fuel mass and the corresponding IMEP increase. Since the second injection is the ignition source in this mode, the mixing process of this injection is very important to promote the auto-ignition event and to suppress the soot formation. Thus, the premixed gasoline mass and ratio can be further increased with higher DI injection pressure, without violating the soot emission constraint. The higher gasoline ratio is also beneficial for PPRR reduction, which is potentially helpful to extend the operating loads. In addition, it is seen that the highest load is achieved with $10 \mathrm{mg} /$ cycle diesel mass, as shown in Figure 10. The reason is that the reactivity and equivalence ratio stratifications are not sufficient at higher diesel injection pressure with $8.0 \mathrm{mg} /$ cycle diesel, resulting in unstable combustion and high COV.

Figure 11 shows the maximum loads that can be obtained with different injection strategies. The operating parameters and emissions corresponding to the points of maximum loads are

TABLE 2 | Operating conditions for the experiments to extend the load with double injection.

\begin{tabular}{ll}
\hline EGR (\%) & $\mathbf{4 5}$ \\
\hline SOl1 ( ${ }^{\circ}$ ATDC) & -55 \\
Mass of diesel (mg/cycle) & $8,10,12$ \\
CA50 ( ${ }^{\circ}$ ATDC) & $8 \sim 9$ \\
Injection pressure (MPa) & $80,100,120,140$
\end{tabular}

presented in Table 3. L-SOI2 strategy has the highest capability in extending the operation range compared to E-single and E-SOI2 cases. By changing the injection strategies from E-single

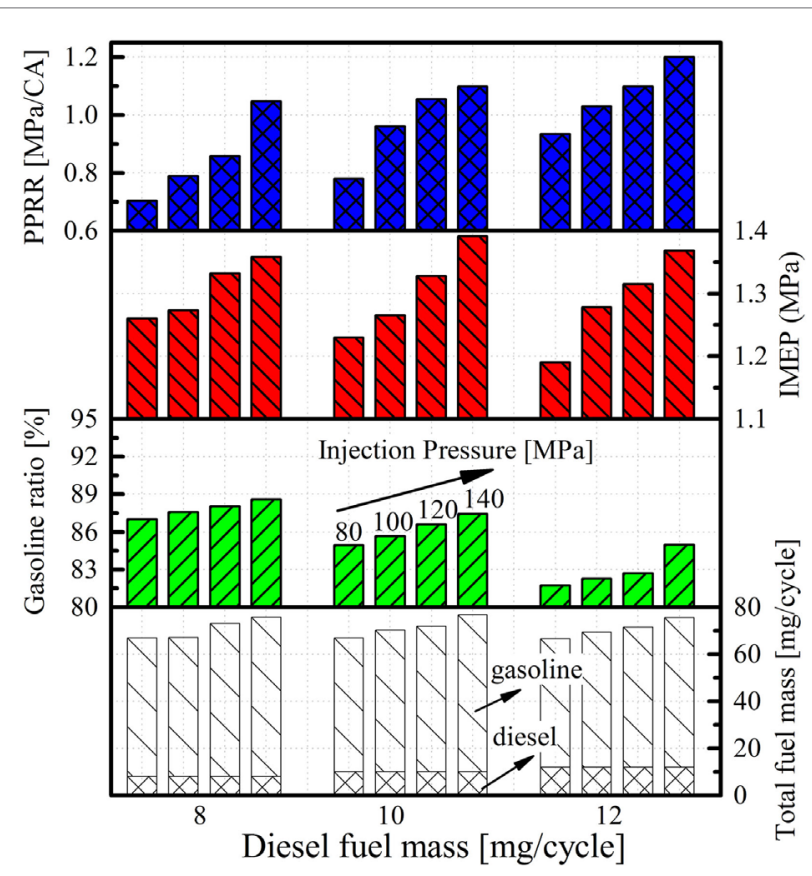

FIGURE 10 | Effects of diesel injection pressure on the maximum achievable load in dual-fuel HPCC with dual-injection.

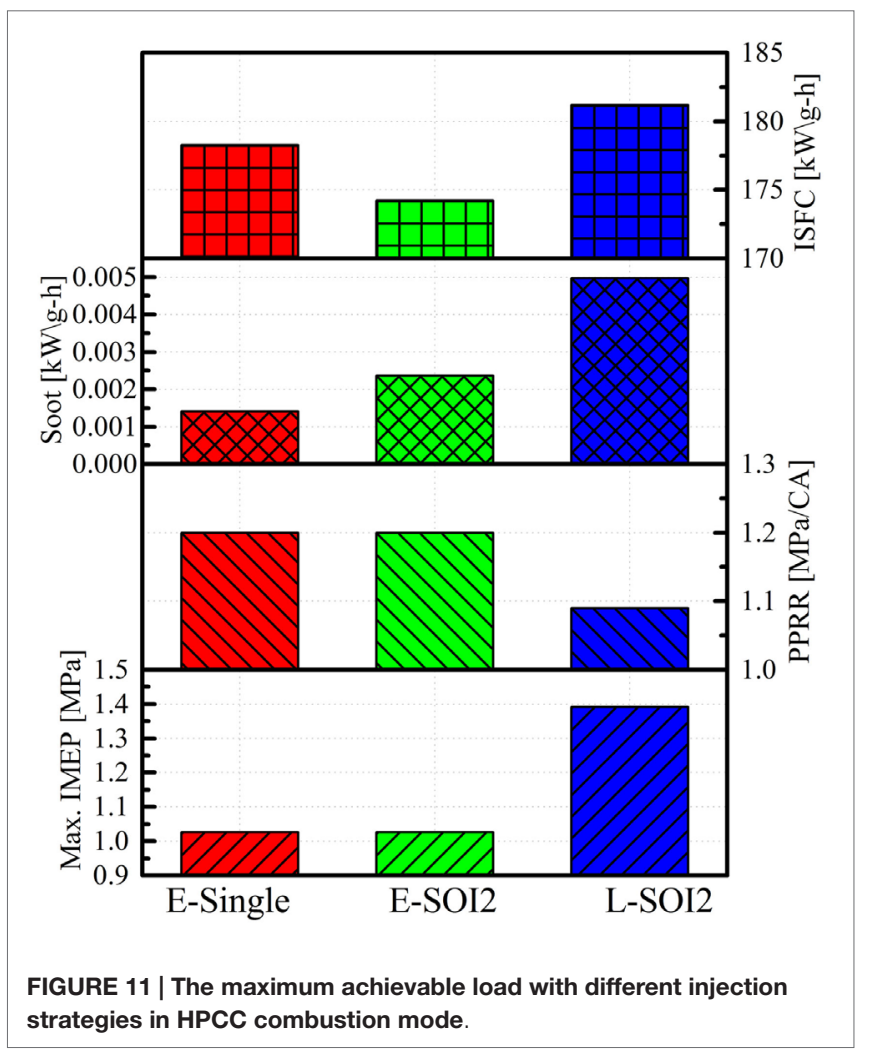


TABLE 3 | The operating parameters and emissions corresponding the maximum load in Figure 11.

\begin{tabular}{|c|c|c|c|}
\hline Injection strategy & E-single & E-SOI2 & L-SOI2 \\
\hline SOl1 ( ${ }^{\circ}$ ATDC) & & -58 & -55 \\
\hline SOI2 ( ${ }^{\circ}$ ATDC) & -35 & -31 & -8 \\
\hline EGR (\%) & 42.5 & 42.5 & 42.5 \\
\hline Gasoline (\%) & 81.7 & 81.3 & 87.5 \\
\hline$P_{\text {inj }}(\mathrm{MPa})$ & 80 & 80 & 140 \\
\hline Soot $(g /(k W h))$ & 0.0014 & 0.0024 & 0.005 \\
\hline $\mathrm{NOx}(\mathrm{g} /(\mathrm{kW} h))$ & 0.17 & 0.21 & 0.11 \\
\hline $\mathrm{CO}(\mathrm{g} /(\mathrm{kW} h))$ & 3.17 & 3.35 & 7.09 \\
\hline $\mathrm{THC}(\mathrm{g} /(\mathrm{kW} h))$ & 3.78 & 4.14 & 4.07 \\
\hline
\end{tabular}

and E-SOI2 to L-SOI2, the IMEP can be increased from 1.026 and 1.027 to $1.391 \mathrm{MPa}$, the constraint factors of extending operation ranges switch from the high PPRR to high soot emission correspondingly.

Compared to other two injection strategies, the late second injection timing (L-SOI2) strategy was most favorable for PPRR reduction because of prolonged combustion duration. Under the operating conditions with optimized parameters, the maximum IMEP can be extended up to $1.391 \mathrm{MPa}$ by using L-SOI2 strategy with increased fuel mass while still maintaining the emissions and PPRR within a given criteria. Further load extension was mainly constrained by the high soot emissions.

\section{Combustion Mode Design Fueled with Dual-Fuel}

The challenges under low load conditions, especially the cold start conditions, are the combustion stability, as well as the fuel economy, UHC, and CO emissions. Under this condition, usually high cetane number fuel is required to ensure the auto-ignition and combustion stability. Mid-load conditions are suitable for dual-fuel combustion concept, ultra-low NOx and soot emissions, together with high ITE can be obtained simultaneously using dual-fuel combustion concept. The major challenges for high load are the pressure rise rate limit or noise control, as well as the NOx and soot emissions.

Based on all these discussions, it can be observed that the dual-fuel strategy offers flexible charge reactivity and stratification controls, which can then be used to achieve flexible combustion mode base on operating conditions. Tong et al. (2013) experimentally explored the combustion mode design on a four-cylinder light-duty diesel engine coupled with both high pressure loop EGR (HPL-EGR) and low pressure loop-EGR (LPL-EGR) systems at $1900 \mathrm{r} / \mathrm{min}$ engine speed. In this study, the PCCI and HPCC/RCCI combustion modes with both HPL-EGR and LPL-EGR systems were compared under different operation conditions. The combustion modes transition was guided by the previous experimental results of single-cylinder engine (Engine $\mathrm{B}$ in Table 1), the process was manually controlled by adjusting fuels injection along with EGR rate. For PCCI combustion mode at low load conditions, the combustion mode transition from conventional mode was realized through advancing the diesel injection timing and increasing the EGR rate, for a given SOI, there exist an optimum EGR rate in term of the emissions and efficiency. The transition to dual-fuel HPCC combustion mode from conventional diesel combustion was realized through increasing gasoline fuel injection duration along with the minor adjustments of diesel injection timing and duration to prevent heavy knocking in the engine. When the engine attained the target load condition, the primary control parameters such as diesel SOI, gasoline ratio, and EGR fraction were balanced for the best performance.

Under low load condition [0.25 MPa break mean effective pressure (BMEP)], the single high cetane number diesel fuel PCCI combustion with either HPL-EGR or LPL-EGR shows fuel economy advantages compared to the conventional combustion and the dual-fuel HPCC/RCCI modes, as shown in Figure 12A. The combustion efficiency of HPCC/RCCI is relatively low (around 93\%) due to the lean premixed low reactivity fuel under this condition.

Under mid-load condition (0.6 MPa BMEP), near-zero soot emission can be obtained due to the advanced diesel injection timing and highly premixed gasoline with dual-fuel HPCC/RCCI mode, the NOx emission can also be controlled to be lower than $0.4 \mathrm{~g} / \mathrm{kW}$-h. The HPL-EGR system in single fuel PCCI mode cannot provide the desired boost pressure and EGR simultaneously, thus high soot emission was observed. The HPL HPCC/RCCI mode demonstrated higher thermal efficiency compared to the LPL HPCC/RCCI mode, UHC, and CO can also be reduced due to the optimized combustion process and low EGR rate. LPL-EGR system is preferred if the load was further increased (higher than 0.85 MPa BMEP). L-HPCC with LPL-EGR system demonstrated longer combustion duration and lower peak HRR compared to the E-HPCC mode, thus are helpful for thermal efficiency improvement and emission reduction. Figure 12B shows that the maximum load can be greatly extended by using the L-HPCC mode compared to the E-HPCC mode with low pressure EGR system.

As discussed above, Ma et al. (2013) showed that the maximum operating limit can be extended to $1.39 \mathrm{MPa}$ IMEP with late SOI2 timing in dual-fuel HPCC/RCCI mode with double-injection strategy. The modeling study of Lim et al. (Lim and Reitz, 2014) used dual DI injectors for combustion phasing control of high load RCCI combustion. In addition to DI diesel event, a second injector was used to directly inject certain amount of gasoline into the cylinder. This work demonstrated that 2.1 MPa IMEP RCCI was achievable using dual DIs in the simulations.

Another combustion strategy to operate the engine in high/ full-load mode is the Partially Premixed Combustion (PPC) with high octane number fuels, which is a typical and representative combustion mode in gasoline compression ignition (GCI) lowtemperature combustion concept. In this combustion mode, the high octane number fuel (such as gasoline) was directly injected into the combustion chamber near TDC. The high auto-ignition resistant and volatility of gasoline could improve the mixing process, while the combustion phasing can be controlled by the injection timing. Kalghatgi et al. (2006) conducted a series studies on PPC combustion mode. Their studies showed that high efficiency (ISFC $178 \mathrm{~g} / \mathrm{kW} \mathrm{h}$ ) and low emissions $\left(\mathrm{NO}_{x} 1.2 \mathrm{~g} / \mathrm{kW} \mathrm{h}\right.$, smoke $0.36 \mathrm{FSN}$ ) can be achieved at 14.86 bar IMEP condition using RON 95 gasoline fuel. The load can be further extended to 15.95 bar 

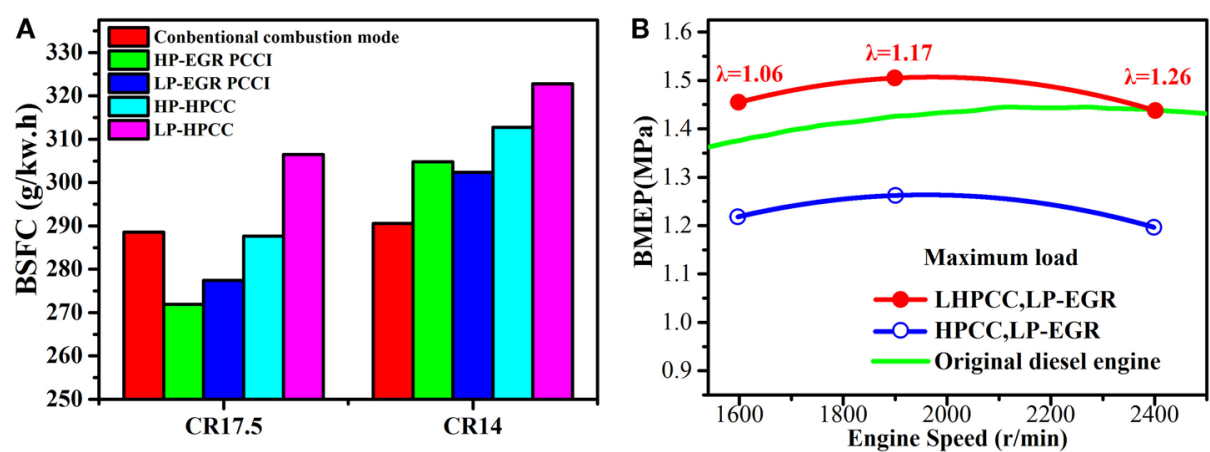

FIGURE 12 | Comparison of (A) BSFC between PCCI and HPCC under low load conditions (0.25 MPa BMEP) and (B) the maximum load between original diesel engine, L-HPCC and HPCC with low pressure EGR.

IMEP when double-injection strategy was used (Kalghatgi et al., 2007). Manente et al. (2010) showed that successful PPC combustion can be achieved in the whole operating range by using RON $<70$ gasoline fuel on a heavy-duty diesel engine, while the low load limit can only be reduced to around 15 bar IMEP when RON 93-100 gasoline fuel was used. The smoke can be reduced to be lower than $0.5 \mathrm{FSN}$ at 25 bar IMEP load condition by running gasoline PPC, combined with optimized EGR rate and air fuel ratio control. Fifty percent effective thermal efficiency can be obtained between 16 and 26 bar IMEP conditions, along with low NOx and soot emissions using two low octane number fuels. However, the soot emissions exceeded the Euro VI and US 2010 legislation limits when the load was higher than 15 bar IMEP. Tuner et al. (2014) further explored the PPC combustion on a multi-cylinder lightduty diesel engine. It was found that by running the gasoline PPC combined with low pressure EGR system, extremely low NOx and soot emissions, together with high ITE (51.1\%) can be obtained. In addition, longer ignition delay, lower PPRR and higher thermal efficiency can be obtained by using double-injection strategy. However, the soot emissions were penalized. The achievable PPC operating range could cover the loads from idle condition to 18 bar IMEP condition when RON 70 gasoline fuel was used. In this combustion mode, the EGR and injection control strategies can be important measures for combustion control. In addition, variable valve timing (VVT) with retarded IVC time to achieve Miller cycle, is another possible way to realize clean and high efficiency combustion in high/full-load mode on diesel engines.

Overall, optimized combustion can be achieved by adopting the dual-fuel combustion concept. Through hybrid combustion mode design, wiz. single fuel PCCI mode at low loads with high cetane number fuel, dual-fuel HPCC mode at medium to high loads, and PPC mode with high octane number fuel at high to full loads, it is possible to realize high efficiency and clean combustion over a wide load range through the combination of combustion modes with proper injection strategy and EGR control.

\section{Conclusion}

In this paper, a review on the combustion mode design with high efficiency and low emissions controlled by the mixture stratification and fuel reactivity that have been conducted in the authors' group is presented. The review starts with the HCCI combustion control through charge reactivity control, followed by the effects of charge stratification on HCCI combustion, and then the dual-fuel compound combustion concept involves both charge reactivity and stratification to achieve effective combustion control, and finally the combustion mode design with dual-fuel strategy is discussed and proposed. The major conclusions can be summarized as follows:

1. in charge reactivity controlled HCCI combustion mode, the charge reactivity greatly affects the combustion characteristics and achievable operating load range. Flexible combustion control and load extension can be achieved by changing the charge reactivity according to the operating conditions in dual-fuel HCCI combustion. High charge reactivity favors the stable operation under low loads and low charge reactivity is helpful for PPRR suppression and load extension. The maximum IMEP can be extended to $0.77 \mathrm{MPa}$ with DME/ methanol dual-fuel compared to 0.30 MPa IMEP with single DME fuel;

2. charge stratification is a potential mechanism for controlling the HCCI combustion. Stronger charge stratification is helpful for PPRR reduction compared to the pure HCCI combustion. However, the major concerns for this single fuel stratified HCCI combustion was the $\mathrm{NOx}$ and $\mathrm{CO}$ emissions. In addition, local temperature (thermal) stratification can also reduce the pressure rise rate through smoothing the reaction rates and extending the operating range in HCCI engines;

3. dual-fuel combustion concept by port injection and DI of two fuels with different reactivity can be used to control both the charge reactivity and stratification. The thermalatmosphere controlled compound combustion concept can be operated by port injection of high cetane number fuel and late DI of high octane number fuel. The operating range of this combustion concept can be extended to high- and full-load conditions. Low CO and UHC emissions can be obtained by controlling the DI timing and DI ratio, while NOx emission can also be controlled through methanol injection strategy optimization; 
4. in the dual-fuel RCCI/HPCC combustion concept, charge reactivity and stratification can be controlled by port injection high octane number fuel and DI high cetane number fuel. Ignition timing, combustion phasing, and pressure rise rate can be effectively manipulated by the coupling control of injection strategy and splitting ratio between the premixed and DI fuels. Late second injection timing in double-injection strategy for DI fuel has the highest potential in extending the operation range compared to the early single injection strategy and early second injection timing in double-injection strategy. The maximum IMEP can be expanded up to $1.391 \mathrm{MPa}$ by using late second injection timing strategy while still maintaining emissions and PPRR within a given criteria;

5. smart combustion mode (hybrid combustion) can be achieved by dual-fuel to get high efficiency with ultra-low NOx and soot emissions in the whole engine operating range. PCCI with long ignition delay should be adopted for diesel-like high cetane number fuel under low load

\section{References}

Chen, Z., Yao, M., Zheng, Z., and Zhang, Q. (2009). Experimental and numerical study of methanol/dimethyl ether dual-fuel compound combustion. Energy Fuels 23, 2719-2730. doi:10.1021/ef8010542

Huang, C., Yao, M., Lu, X., and Huang, Z. (2009). Study of dimethyl ether homogeneous charge compression ignition combustion process using a multi-dimensional computational fluid dynamics model. Int. J. Therm. Sci. 48, 1814-1822. doi:10.1016/j.ijthermalsci.2009.02.006

Kalghatgi, G., Risberg, P., and Angström, H. (2006). Advantages of Fuels with High Resistance to Auto-Ignition in Late-Injection, Low-Temperature, Compression Ignition Combustion. SAE Technical Paper, 2006-01-3385. Toronto: SAE International. doi:10.4271/2006-01-3385

Kalghatgi, G., Risberg, P., and Angström, H. (2007). Partially Pre-Mixed AutoIgnition of Gasoline to Attain Low Smoke and Low Nox at High Load in a Compression Ignition Engine and Comparison with a Diesel Fuel. SAE Technical Paper, 2007-01-0006. Cape Town: SAE International. doi:10.4271/2007-01-0006

Lim, J. H., and Reitz, R. D. (2014). High load (21 Bar IMEP) dual fuel RCCI combustion using dual direct injection. J. Eng. Gas Turbine. Power 136, 101514-101514. doi:10.1115/1.4027361

Liu, H., Wang, X., Zheng, Z., Gu, J., Wang, H., and Yao, M. (2014). ). Experimental and simulation investigation of the combustion characteristics and emissions using n-butanol/biodiesel dual-fuel injection on a diesel engine. Energy 74, 741-752. doi:10.1016/j.energy.2014.07.041

Liu, H., Yao, M., Zhang, B., and Zheng, Z. (2008). Effects of inlet pressure and octane numbers on combustion and emissions of a homogeneous charge compression ignition (HCCI) engine. Energy Fuels 22, 2207-2215. doi:10.1021/ ef800197b

Liu, H., Yao, M., Zhang, B., and Zheng, Z. (2009). Influence of fuel and operating conditions on combustion characteristics of a homogeneous charge compression ignition engine. Energy Fuels 23, 1422-1430. doi:10.1021/ef800950c

Liu, H., Yao, M., Zheng, Z., and Wang, Y. (2010). An Investigation of Different Ported Fuel Injection Strategies and Thermal Stratification in HCCI Engines Using Chemiluminescence Imaging. SAE Technical Paper, 2010-01-0163. Detroit: SAE International. doi:10.4271/2010-01-0163

Liu, H., Zhang, P., Li, Z., Luo, J., Zheng, Z., and Yao, M. (2011). Effects of temperature inhomogeneities on the HCCI combustion in an optical engine. Appl. Therm. Eng. 31, 2549-2555. doi:10.1016/j.applthermaleng.2011.04.020

Ma, S., Zheng, Z., Liu, H., Zhang, Q., and Yao, M. (2013). Experimental investigation of the effects of diesel injection strategy on gasoline/diesel dual-fuel combustion. Appl. Energy 109, 202-212. doi:10.1016/j.apenergy.2013.04.012

Manente, V., Zander, C., Johansson, B., and Tunestal, P. (2010). An Advanced Internal Combustion Engine Concept for Low Emissions and High Efficiency from Idle to conditions. Gasoline/diesel dual-fuel with early single injection or double-injection with early second injection timing, combined with optimized EGR control, shows the highest potential to maximize the thermal efficiency and to minimize the pollutant emissions under medium load conditions. RCCI and L-HPCC have shown the potential to extend the operating range to higher loads through both fuel property and injection strategy optimizations. PPC mode with high octane number fuel combined with EGR is a promising pathway to realize clean and high efficiency combustion in high/full-load mode on diesel engines.

\section{Acknowledgments}

The authors acknowledge financial support provided by the National Science Foundation of China through the project of international cooperation and exchange (51320105008).

Max Load Using Gasoline Partially Premixed Combustion. SAE Technical Paper, 2010-01-2198. Rio de Janeiro: SAE International. doi:10.4271/2010-01-2198

Reitz, R. D. (2013). Directions in internal combustion engine research. Combust. Flame 160, 1-8. doi:10.1016/j.combustflame.2012.11.002

Reitz, R. D., and Duraisamy, G. (2015). Review of high efficiency and clean reactivity controlled compression ignition (RCCI) combustion in internal combustion engines. Prog. Energy Combust. Sci. 46, 12-71. doi:10.1016/j. pecs.2014.05.003

Richter, M., Engström, J., Franke, A., and Aldén, M. (2010). The Influence of Charge Inhomogeneity on the HCCI Combustion Process. SAE Technical Paper, 2000-012868. Tulsa: SAE International. doi:10.4271/2000-01-2868

Tong, L., Liu, H., Zheng, Z., and Yao, M. (2013). The Design and Optimized Combination of Combustion Modesover Full-Load Range in a Multi-Cylinder Light-Duty Engine. SAE Technical Paper, 2013-01-2623. Seoul: SAE International. doi:10.4271/2013-01-2623

Tuner, M., Johansson, T., Aulin, H., and Tunestal, P. (2014). Multi Cylinder Partially Premixed Combustion Performance Using Commercial Light-Duty Engine Hardware. SAE Technical Paper, 2014-01-2680. Birmingham: SAE International. doi:10.4271/2014-01-2680

Yang, B., Li, S., Zheng, Z., Yao, M., and Cheng, W. (2012). A Comparative Study on Different Dual-Fuel Combustion Modes Fuelled with Gasoline and Diesel. SAE Technical Paper, 2012-01-0694. Detroit: SAE International. doi:10.4271/2012-01-0694

Yang, B., Yao, M., Cheng, W. K., Li, Y., Zheng, Z., and Li, S. (2014). Experimental and numerical study on different dual-fuel combustion modes fuelled with gasoline and diesel. Appl. Energy 113, 722-733. doi:10.1016/j.apenergy.2013.07.034

Yao, M., Chen, Z., Zheng, Z., Zhang, B., and Xing, Y. (2005a). Effect of EGR on HCCI Combustion fuelled with Dimethyl Ether (DME) and Methanol DualFuels. SAE Technical Paper, 2005-01-3730. San Antonio: SAE International. doi:10.4271/2005-01-3730

Yao, M., Qin, J., and Zheng, Z. (2005b). Numerical study of the combustion mechanism of a homogeneous charge compression ignition engine fuelled with dimethyl ether and methane, with a detailed kinetics model. Proc. Inst. Mech. Eng. D J. Automobile Eng. 219, 1213-1223. doi:10.1243/095440705x34810

Yao, M., Zheng, Z., and Qin, J. (2005c). Experimental study on homogeneous charge compression ignition combustion with fuel of dimethyl ether and natural gas. J. Eng. Gas Turbine. Power 128, 414-420. doi:10.1115/1.2130731

Yao, M., Chen, Z., Zheng, Z., and Zhang, Q. (2007a). Investigation of the Effects of Injection Timing on Thermo-Atmosphere Combustion of Methanol. SAE Technical Paper, 2007-01-0197. Detroit: SAE International. doi:10.4271/200701-0197

Yao, M., Huang, C., and Zheng, Z. (2007b). Multidimensional numerical simulation on dimethyl ether/methanol dual-fuel homogeneous charge compression 
ignition (HCCI) engine combustion and emission processes. Energy Fuels 21, 812-821. doi:10.1021/ef0604745

Yao, M., Zhang, B. O., Zheng, Z., and Chen, Z. (2007c). Experimental study on homogeneous charge compression ignition combustion with primary reference fuel. Combust. Sci. Technol. 179, 2539-2559. doi:10.1080/00102200701486907

Yao, M., Zheng, Z., Chen, Z., and Zhang, B. (2007d). Experimental study on homogeneous charge compression ignition operation by burning dimethyl ether and methanol. Int. J. Green Energy 4, 283-300. doi:10.1080/15435070701193134

Yao, M., Liu, H., Zhang, B., and Zheng, Z. (2008). An Investigation on the Effects of Fuel Chemistry and Engine Operating Conditions on HCCI Engine. SAE Technical Paper, 2008-01-1660. Shanghai: SAE International. doi:10.4271/2008-01-1660

Yao, M., and Qin, J. (2004). Simulating the Homogeneous Charge Compression Ignition Process Using a Detailed Kinetic Model for Dimethyl Ether (DME) and Methane Dual Fuel. SAE Technical Paper, 2004-01-2951. San Diego: SAE International. doi:10.4271/2004-01-2951

Yao, M., and Zheng, Z. (2007). A Numerical Investigation on Effects of Charge Stratification on HCCI Combustion. SAE Technical Paper, 2007-01-4132. Chicago: SAE International. doi:10.4271/2007-01-4132

Yao, M., Zheng, Z., and Liu, H. (2009). Progress and recent trends in homogeneous charge compression ignition (HCCI) engines. Prog. Energy Combust. Sci. 35, 398-437. doi:10.1016/j.pecs.2009.05.001

Yao, M., Zheng, Z., Zhang, B., and Chen, Z. (2004). The Effect of PRF Fuel Octane Number on HCCI Operation. SAE Technical Paper, 2004-01-2992. San Diego: SAE International. doi:10.4271/2004-01-2992
Yao, M.-F., Zheng, Z.-L., and Liang, X. (2006). Numerical Study on the Chemical Reaction Kinetics of DME/Methanol for HCCICombustion Process. SAE Technical Paper, 2006-01-1521. Detroit: SAE International. doi:10.4271/2006-01-1521

Zheng, Z., and Yao, M. (2007). Numerical simulation of the effects of charge stratification on combustion and emissions. Energy Fuels 21, 2018-2026. doi:10.1021/ ef070071k

Zheng, Z., and Yao, M. (2009). Charge stratification to control HCCI: experiments and CFD modeling with n-heptane as fuel. Fuel 88, 354-365. doi:10.1016/j. fuel.2008.09.002

Zheng, Z., Yao, M., Chen, Z., and Zhang, B. (2004). Experimental Study on HCCI Combustion of Dimethyl Ether(DME)/Methanol Dual Fuel. SAE Technical Paper, 2004-01-2993. San Diego: SAE International. doi:10.4271/2004-01-2993

Conflict of Interest Statement: The authors declare that the research was conducted in the absence of any commercial or financial relationships that could be construed as a potential conflict of interest.

Copyright (c) 2015 Wang, Zheng, Liu and Yao. This is an open-access article distributed under the terms of the Creative Commons Attribution License (CC BY). The use, distribution or reproduction in other forums is permitted, provided the original author(s) or licensor are credited and that the original publication in this journal is cited, in accordance with accepted academic practice. No use, distribution or reproduction is permitted which does not comply with these terms. 